\title{
High grain quality accessions within a maize drought tolerant core collection
}

\author{
Dragana Ignjatovic-Micic * Marija Kostadinovic, Sofija Bozinovic, Violeta Andjelkovic, Jelena Vancetovic
}

Maize Research Institute Zemun Polje, S. Bajica 1 - 11085 Belgrade - Serbia.

*Corresponding author <idragana@mrizp.rs>

Edited by: Natalia de-Leon

Received Abril 11, 2013

Accepted March 30, 2014
ABSTRACT: Maize (Zea mays L.) landraces are an important source of genes for improving commercial germplasm. Today, drought tolerance and grain quality are major challenges in maize cultivation due to climatic changes and population growth. The Maize Research Institute genebank has a drought tolerant collection, which includes 13 landraces (from the former Yugoslavia) and 12 introduced populations (from different countries). These accessions were analyzed for protein, oil, starch and tryptophan contents, in order to identify drought tolerant accessions with high grain quality. Also, simple sequence repeat (SSR) analysis with specific primers for opaque2 recessive allele (o2) was carried out. All analyzed accessions showed high levels of protein. Oil content ranged from $3.75 \%$ to $5.40 \%$ and starch content from $67.5 \%$ to $71.30 \%$. Average protein content was not different $(p<0.01)$ between landraces and introduced populations. Starch and oil contents were higher in introduced populations at $0.84 \%$ and $0.39 \%$, respectively $(p<$ 0.01). Twenty-three accessions had high levels of tryptophan content. A high percentage of kernel type 1 and 2 indicated the presence of endosperm hardness modifier genes. Recessive 02 allele was found in most of the accessions. Absence of 02 in some high tryptophan accessions indicated action of another mutation. In two high tryptophan accessions an unknown band was detected. Absence of negative correlations between proteins, tryptophan and oil makes certain accessions suitable for use in the simultaneous improvement of target genotypes for these traits. Identified drought tolerant, high quality accessions can be used in breeding programs aimed at nutritional improvement of maize grown under drought conditions.

Keywords: opaque2, protein, starch, oil, tryptophan

\section{Introduction}

It has been predicted that by 2020 the demand for maize (Zea mays L.) in developing countries will overtake the demand for both wheat and rice - by 2025 maize is likely to become the crop with the greatest production globally (Rosegrant et al., 2008).

Maize cultivation has been primarily aimed at increasing yield potential and stability under different environmental conditions. However, the quality of maize kernel composition is extremely important for human and animal nutrition and chemical characterization of the grain should become an inevitable component of maize cultivation programs. The relative chemical composition (e.g. protein, oil, and starch contents) in grains defines the purpose for which maize will be used (White et al., 2001; Baye et al., 2006). For example, quality protein maize (QPM) has increased amounts of essential amino acids lysine and tryptophan, and thus increases the nutritional value for protein-deficient populations (Krivanek et al., 2007), while in animal feed significantly increases the rate of pig weight gain (Sofi et al., 2009).

Redesigning maize for improved kernel qualities may require introduction of novel alleles not presently found in commercial maize germplasm. Teosinte and landraces harbor phenotypic variation that can facilitate genetic dissection of kernel traits and grain quality, ultimately leading to improvement via traditional plant cultivation and/or genetic engineering (Flint-Garcia et al., 2009). Using teosinte and landrace accessions as sourc- es of genetic variation for maize breeding is especially significant for genes that have limited or no variation remaining in modern inbreds (Wright et al., 2005; Yamasaki et al., 2005).

Maize Research Institute Zemun Polje (MRI) has a gene bank which conserves 2,217 landraces from the former Yugoslavia and 3,258 accessions from 40 countries. Surveying for drought tolerant accessions has resulted in the establishment of a drought tolerant core collection (Babic et al., 2011). Herein, the results of grain quality analysis of accessions from this core collection are presented. This study was aimed to: i) identify potential accessions with alleles for both drought tolerance and grain quality (macronutrient content, tryptophan content and kernel type) and ii) identify accessions that carry the recessive opaque 2 allele for high tryptophan content, with specific simple sequence repeat (SSR) primers.

\section{Materials and Methods}

\section{Plant material}

Thirteen landraces (accessions L1 to L13) and 12 introduced populations (accessions IP1 to IP12) from the drought tolerant core collection were analyzed for grain quality characteristics. The landraces /originating from different parts of the former Yugoslavia) belong to the following seven agro-ecological groups: Derived flints (L2), Mediterranean flints (L11), Eight rowed soft dents (L6), Flinty Dents (L8), Denty Flints (L13), White flinty dents Moravac (L1, L9) and Dents type of USA Corn Belt dents (L3, L4, L5, L7, L10, L12). The introduced popula- 
tions (landraces from different parts of the world) originate from Iran (IP1 and IP2), France (IP3), the former USSR (IP4), Bulgaria (IP5), Italy (IP7 and IP8), Pakistan (IP9) and the USA (IP10). For three accessions (IP6, IP11 and IP12) there were no data on the origin.

The twenty-five accessions from the elite drought tolerant core were multiplied (via pair crossing, i.e. fullsibling) in two replications, according to a completely randomized block design (RCBD), in 2009. At least 80 ears were collected per multiplied population. Each multiplied population was dried and shelled and samples of kernels from the centre of the ear were prepared for grain quality analysis.

\section{NIR analysis}

Near Infrared Spectroscopy (NIR) analysis was used for starch, oil and protein content analysis. The samples of non-destructed seed (300 g per sample) from each replicate of multiplied seed were scanned twice. Spectra were collected between $800 \mathrm{~nm}$ and 1,100 nm.

\section{Tryptophan and QI analysis}

Genotypes were represented with two samples, each consisting of 30 randomly chosen kernels from ten competitive plants. Kernels were dried in a thermostat at $65{ }^{\circ} \mathrm{C}$ overnight $(16-18 \mathrm{~h})$ and milled in a Cyclone sample mill. The flour was defatted by hexane treatment for four hours in a Soxhlet extractor.

Tryptophan content was determined using the colorimetric method (Nurit et al., 2009). The color was developed in a reaction of flour hydrolysate (obtained by overnight digestion with papain solution at $65^{\circ} \mathrm{C}$ ) with $2 \mathrm{~mL}$ of reagent containing $56 \mathrm{mg}$ of $\mathrm{Fe}^{3+}$ dissolved in $1 \mathrm{~L}$ of glacial acetic acid and $2 \mathrm{~mL}$ of $15 \mathrm{M} \mathrm{H}_{2} \mathrm{SO}_{4}$. After incubation at $65{ }^{\circ} \mathrm{C}$ for $15 \mathrm{~min}$, absorbance was read at $560 \mathrm{~nm}$. Tryptophan content was calculated using a standard calibration curve, developed with the known amounts of tryptophan, ranging from 0 to 30 $\mu \mathrm{g} \mathrm{mL} \mathrm{m}^{-1}$.

In order to obtain accurate quality index (QI) values, protein content was also determined in the samples used for tryptophan analysis by the standard Kjeldahl method based on nitrogen determination (Vivek et al., 2008). The protein was estimated from the nitrogen value as $\%$ protein $=\%$ nitrogen $\times 6.25$ (conversion factor for maize).

Quality index (QI), i.e. tryptophan to protein ratio in the sample, was calculated as QI $=100 \times$ tryptophan content in the sample / protein content in the sample

\section{Identification of kernel types}

For each genotype 200 kernels were visually scored using a light table (Vivek et al., 2008). The scoring scale defined kernel types, from type 1 (completely translucent, with no opaqueness) to type 5 (completely opaque). Kernels with $25 \%$ opaqueness were scored as type 2 , while types 3 and 4 were $50 \%$ and $75 \%$ opaque kernels, respectively.

\section{Statistical analysis}

All chemical analyses were performed in two replicates and the results were statistically analyzed. One factorial analysis of variance (ANOVA) for trials set up according to the RCB design was carried out. Fisher's least significant difference (LSD) test was used to test the significance of differences between the observed means. All statistical analyses were done using MSTATC software. Students' t-tests between average values of landraces and introduced populations were performed to determine statistical differences in the chemical composition and kernel type of the two groups of accessions. Pearson's correlation coefficient was used for determining correlations between protein, starch, oil, tryptophan, QI and kernel types, as well as between protein contents as determined by the NIR and Kjeldah method.

\section{SSR analysis}

SSR analysis of the 25 accessions was carried out using a DNA-pooled sampling strategy (bulk analysis). Each accession was represented by 30 individual seeds, which were grounded into flour. For bulk analysis equal amounts of the flour per accession were pooled into a single sample. Also, a subset of six accessions was analyzed for individual seeds, in order to get insight into distribution of the 02 allele within an accession. The choice of accessions was based on electrophoregram profiles of bulk analysis and tryptophan content.

PCR (polymerase chain reaction) amplification was performed on the DNA isolated from 25 bulked populations and 180 individual samples (30 seeds from six accessions) according to Rogers and Bendich (1988), with two primers specific for opaque 2 gene - phi057 and umc1066. The amplification reaction was carried out in $20 \mu \mathrm{L}$ reaction volume containing $1 \mathrm{x}$ enzyme buffer, 3 $\mathrm{mM} \mathrm{MgCl}{ }_{2}, 200 \mu \mathrm{M}$ dNTPs, $0.25 \mu \mathrm{M}$ primers, $1.25 \mathrm{U}$ Taq polymerase and $50 \mathrm{ng}$ of DNA. The amplification profiles were as follows: an initial denaturation at 94 ${ }^{\circ} \mathrm{C} / 2 \mathrm{~min}$, followed by 40 cycles each of denaturation at $94{ }^{\circ} \mathrm{C} / 1 \mathrm{~min}$, annealing at $60^{\circ} \mathrm{C} / 2 \mathrm{~min}$ and extension at $72{ }^{\circ} \mathrm{C} / 2 \mathrm{~min}$, with final extension at $72{ }^{\circ} \mathrm{C} / 10 \mathrm{~min}$. Amplified fragments were separated on $12 \%$ polyacrylamide gels. After electrophoresis, gels were stained with ethidium bromide, photographed and analyzed using the BioDocAnalyze (Biometra) gel documentation system.

\section{Results}

\section{Biochemical analyses}

NIR analysis revealed high levels of protein (from $10.90 \%$ to $13.85 \%$ ) in all accessions (Table 1). Starch levels were in the range from $67.5 \%$ to $71.30 \%$ and content over $70 \%$ was detected only among five introduced populations (IP3, IP4, IP10, IP11 and IP12). Oil content was in the range from low $(3.75 \%)$ to high $(5.40 \%)$. In one landrace (L1) and three introduced populations (IP2, IP3 and IP8) oil content was over $5.0 \%$. Average protein content in landraces and introduced populations was 
Table 1 - Oil, starch, protein and tryptophan contents, quality index (QI) and kernel type scores of the landraces and introduced populations from the drought tolerant core collection. The results are presented as a percentage of dry matter.

\begin{tabular}{|c|c|c|c|c|c|c|c|}
\hline Accession & Protein NIR & Starch & Oil & Protein Kjeldahl & Tryptophan & QI & Kernel type score \\
\hline \multirow{2}{*}{\multicolumn{8}{|c|}{ Landraces }} \\
\hline & & & & & & & \\
\hline $\mathrm{L} 1$ & $12.40^{\mathrm{bc}}$ & $67.60^{\text {cd }}$ & $5.40^{\mathrm{a}}$ & $13.46^{b}$ & $0.072^{\text {cde }}$ & $0.53^{\mathrm{ef}}$ & 1.42 \\
\hline L2 & $13.85^{\mathrm{a}}$ & $68.65^{\mathrm{bcd}}$ & $4.15^{\mathrm{de}}$ & $13.44^{b}$ & $0.077^{\mathrm{bcd}}$ & $0.57^{\mathrm{de}}$ & 1.50 \\
\hline L3 & $12.30^{\mathrm{bc}}$ & $67.90^{\mathrm{cd}}$ & $4.80^{\mathrm{b}}$ & $13.56^{\mathrm{b}}$ & $0.079^{a b c d}$ & $0.58^{\text {cde }}$ & 1.98 \\
\hline L4 & $11.05^{\text {de }}$ & $69.55^{\mathrm{ab}}$ & $4.75^{\mathrm{bc}}$ & $11.84^{\mathrm{gh}}$ & $0.081^{\mathrm{abc}}$ & $0.69^{\mathrm{ab}}$ & 1.98 \\
\hline L5 & $12.15^{\mathrm{bcd}}$ & $69.35^{\mathrm{ab}}$ & $4.20^{\text {cde }}$ & $12.58^{d}$ & $0.080^{\mathrm{abcd}}$ & $0.64^{\mathrm{abcd}}$ & 1.78 \\
\hline L6 & $11.05^{\text {de }}$ & $69.95^{\mathrm{a}}$ & $3.90^{e}$ & $12.17^{e}$ & $0.073^{\text {bcde }}$ & $0.60^{\text {bcde }}$ & 1.64 \\
\hline L7 & $12.90^{\mathrm{bc}}$ & $68.70^{\mathrm{abcd}}$ & $3.75^{\mathrm{e}}$ & $14.29^{a}$ & $0.065^{\mathrm{e}}$ & $0.46^{\dagger}$ & 1.25 \\
\hline L8 & $10.90^{\text {ef }}$ & $69.55^{\mathrm{ab}}$ & $3.90^{\mathrm{e}}$ & $11.92^{\mathrm{fg}}$ & $0.082^{\mathrm{ab}}$ & $0.69^{a}$ & 1.74 \\
\hline L9 & $13.05^{\mathrm{ab}}$ & $67.95^{\mathrm{cd}}$ & $4.00^{\mathrm{de}}$ & $13.35^{\mathrm{b}}$ & $0.086^{a}$ & $0.65^{\mathrm{abcd}}$ & 1.76 \\
\hline L10 & $11.00^{\text {ef }}$ & $68.35^{\mathrm{bcd}}$ & $3.75^{\mathrm{e}}$ & $11.69^{\mathrm{h}}$ & $0.081^{a b c}$ & $0.69^{a}$ & 1.70 \\
\hline L11 & $12.35^{\mathrm{bc}}$ & $67.50^{d}$ & $4.75^{b}$ & $12.11^{\mathrm{ef}}$ & $0.081^{a b c}$ & $0.67^{a b c}$ & 1.96 \\
\hline $\mathrm{L} 12$ & $12.45^{\mathrm{bc}}$ & $68.85^{a b c}$ & $4.45^{\mathrm{bcd}}$ & $12.80^{c}$ & $0.081^{a b c}$ & $0.63^{\mathrm{abcd}}$ & 1.94 \\
\hline L13 & $11.50^{\text {cde }}$ & $68.85^{\mathrm{abc}}$ & $4.10^{\mathrm{de}}$ & $11.20^{i}$ & $0.072^{\mathrm{de}}$ & $0.65^{\mathrm{abcd}}$ & 1.66 \\
\hline Average & 12.07 & 68.68 & 4.3 & 12.65 & 0.078 & 0.62 & 1.72 \\
\hline SD & 1.05 & 0.82 & 0.49 & 0.90 & 0.006 & 0.07 & 0.22 \\
\hline $\mathrm{LSD}_{0.01}$ & 0.95 & 1.30 & 0.55 & 0.22 & 0.009 & 0.09 & - \\
\hline \multicolumn{8}{|c|}{ Introduced populations } \\
\hline IP1 & $11.90^{\mathrm{bc}}$ & $69.65^{\mathrm{cd}}$ & $4.65^{b c}$ & $12.24^{d}$ & $0.084^{\mathrm{ab}}$ & $0.68^{\mathrm{ab}}$ & 2.26 \\
\hline IP2 & $11.10^{c}$ & $68.20^{\mathrm{fg}}$ & $5.05^{\mathrm{ab}}$ & $11.65^{\mathrm{e}}$ & $0.088^{\mathrm{a}}$ & $0.76^{\mathrm{a}}$ & 1.84 \\
\hline IP3 & $11.40^{c}$ & $70.25^{\mathrm{bc}}$ & $5.25^{\mathrm{a}}$ & $12.14^{\mathrm{d}}$ & $0.070^{\mathrm{bc}}$ & $0.58^{\mathrm{bcd}}$ & 1.54 \\
\hline IP4 & $11.85^{\mathrm{bc}}$ & $70.40^{\mathrm{bc}}$ & $4.30^{\mathrm{cd}}$ & $13.00^{c}$ & $0.084^{\mathrm{ab}}$ & $0.64^{\mathrm{abc}}$ & 1.64 \\
\hline IP5 & $12.00^{\mathrm{bc}}$ & $68.95^{\text {def }}$ & $4.90^{\mathrm{ab}}$ & $12.80^{c}$ & $0.086^{\mathrm{a}}$ & $0.67^{\mathrm{ab}}$ & 1.54 \\
\hline IP6 & $13.45^{\mathrm{a}}$ & $68.00^{\mathrm{g}}$ & $4.65^{b c}$ & $12.84^{c}$ & $0.069^{c}$ & $0.54^{\text {cd }}$ & 1.24 \\
\hline IP7 & $12.80^{\mathrm{ab}}$ & $69.10^{\text {de }}$ & $4.85^{\mathrm{abc}}$ & $14.06^{\mathrm{a}}$ & $0.072^{\mathrm{bc}}$ & $0.51^{\mathrm{d}}$ & 1.56 \\
\hline IP8 & $12.80^{\mathrm{ab}}$ & $68.35^{\mathrm{efg}}$ & $5.35^{\mathrm{a}}$ & $12.78^{c}$ & $0.088^{a}$ & $0.69^{\mathrm{ab}}$ & 1.60 \\
\hline IP9 & $13.70^{\mathrm{a}}$ & $68.05^{\mathrm{g}}$ & $4.65^{\mathrm{bc}}$ & $13.27^{\mathrm{b}}$ & $0.071^{\mathrm{bc}}$ & $0.53^{\mathrm{cd}}$ & 1.70 \\
\hline IP10 & $11.45^{c}$ & $70.75^{\mathrm{ab}}$ & $4.60^{\mathrm{bc}}$ & $11.45^{\mathrm{e}}$ & $0.072^{\mathrm{bc}}$ & $0.63^{\mathrm{bc}}$ & 1.50 \\
\hline IP11 & $11.55^{c}$ & $71.25^{\mathrm{a}}$ & $4.30^{\mathrm{cd}}$ & $12.23^{d}$ & $0.075^{a b c}$ & $0.61^{\mathrm{bcd}}$ & 1.68 \\
\hline IP12 & $11.40^{c}$ & $71.30^{\mathrm{a}}$ & $3.80^{d}$ & $12.32^{\mathrm{d}}$ & $0.071^{\mathrm{bc}}$ & $0.58^{\mathrm{bcd}}$ & 2.02 \\
\hline Average & 12.12 & 69.52 & 4.7 & 12.56 & 0.077 & 0.62 & 1.68 \\
\hline SD & 1.03 & 1.23 & 0.43 & 0.70 & 0.008 & 0.08 & 0.26 \\
\hline $\mathrm{LSD}_{0.01}$ & 0.95 & 0.85 & 0.60 & 0.27 & 0.014 & 0.12 & - \\
\hline \multicolumn{8}{|l|}{$\overline{\text { Total }(\mathrm{L}+\mathrm{IP})}$} \\
\hline Average & 12.09 & 69.08 & 4.49 & 12.61 & 0.078 & 0.62 & 1.70 \\
\hline $\mathrm{SD}$ & 0.87 & 1.10 & 0.50 & 0.80 & 0.007 & 0.07 & 0.24 \\
\hline $\mathrm{LSD}_{0.01}$ & 0.86 & 0.61 & 0.69 & 0.21 & 0.012 & 0.10 & - \\
\hline t-test (L vs. IP) & ns & ** & ** & ns & ns & $\mathrm{ns}$ & ns \\
\hline
\end{tabular}

NIR- Near Infrared Spectroscopy; SD - standard deviation; LSD $_{0.01}$ - least significant difference at $p<0.01$; ailMeans followed by the same letter within the same columns are not different $(p<0.01) ;{ }^{* *}$ - significant at $p<0.01$; ns - statistically not significant.

$12.07 \%$ and $12.12 \%$, respectively, and the difference between them was not significant. On the other hand, starch and oil contents were higher in introduced populations at $0.84 \%$ and $0.39 \%$, respectively $(p<0.01)$.

Protein content determined by the Kjeldahl method was also high in all accessions (11.20\% to $14.29 \%$ ) and on average higher when compared to the NIR meth- od, but the difference was not significant. Twenty-three accessions had tryptophan content over $0.070 \%(0.070$ $\%$ to $0.088 \%)$. One landrace (L7) and one introduced population (IP6) had the lowest values for tryptophan $(0.065 \%$ and $0.069 \%$, respectively). Most of the accessions had medium QI values (0.60 to 0.69). Four landraces and five introduced populations showed QI below 
0.60 , while the highest QI of 0.76 was determined for IP2 introduced population.

Correlations between measured macronutrients, tryptophan, QI and kernel types are given in Table 2. Protein content values determined by both the NIR and Kjeldahl method were used for correlation calculations. Pearson's correlation coefficient for these two methods was 0.751 and was significant at $p<0.01$ (not presented in the table).

Proteins determined by NIR showed negative correlation with starch and QI $(p<0.01)$. Likewise, proteins determined with Kjeldahl method showed the same negative correlations, but at $p<0.05$ and $p<0.01$, respectively. Positive correlations were determined between tryptophan content and QI $(p<0.01)$, as well as between tryptophan content and kernel type $(p<0.05)$. Also, QI showed positive correlation with kernel type $(p<0.05)$.

\section{Identification of kernel types}

Kernel type scores of the analyzed accessions were high (representing hard endosperm), in the range from 1.25 to 1.98 for landraces and 1.24 to 2.26 for introduced populations (Table 1). No differences between landraces and introduced populations were found. The most frequent were kernel type 1 (over $40 \%$ ) and 2 (over $30 \%$ ), making a total of $84 \%$ within landraces and $82 \%$ within introduced populations. Kernel type 3 was present in 15 $\%$ and $17 \%$, respectively (Figure 1). Types 1, 2 and 3 were detected in all accessions. Kernel type 4 was found in three landraces (L4 - 4 \%, L10 - $2 \%$ and L11- $10 \%$ ) and two introduced populations (IP8 - $2 \%$ and IP11 - 2 $\%)$. Completely opaque kernels (type 5) were not found in any of the accessions analyzed.

\section{SSR analysis}

Marker phi057 was monomorphic for the accessions analyzed and could not be used for identification of opaque2 recessive allele (o2). Umc1066 was polymorphic and this marker identified accessions which harbor 02 . Illustration of homozygous and heterozygous accessions for opaque2 identified with bulk analysis is given in Figure 2. Opaque2 recessive allele was found in all accessions, except L7, IP2 and IP6 (L7 and IP6 are not illustrated in Figure 2). This locus was homozygous recessive (o202) in L1, L3, L5, L8 and L9 accessions and heterozygous (O2o2) in the remaining seven landrace accessions. Among the introduced populations, opaque 2 was found to be homozygous recessive in IP7, heterozygous in nine and homozygous dominant (O2O2) in IP6 accessions. IP2 accession was heterozygous with dominant $\mathrm{O} 2$ and an unknown allele (UA) positioned between 02 and $\mathrm{O} 2$ bands.

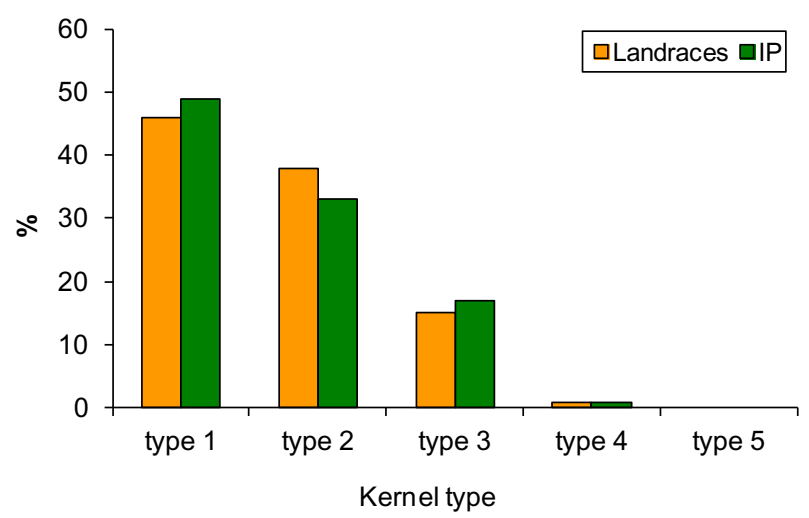

Figure 1 - Percentage of different kernel types within the analyzed landraces and introduced populations. Type 1- $0 \%$ opaque; type $2-25 \%$ opaque; type $3-50 \%$ opaque; type $4-75 \%$ opaque and type $5-100 \%$ opaque.
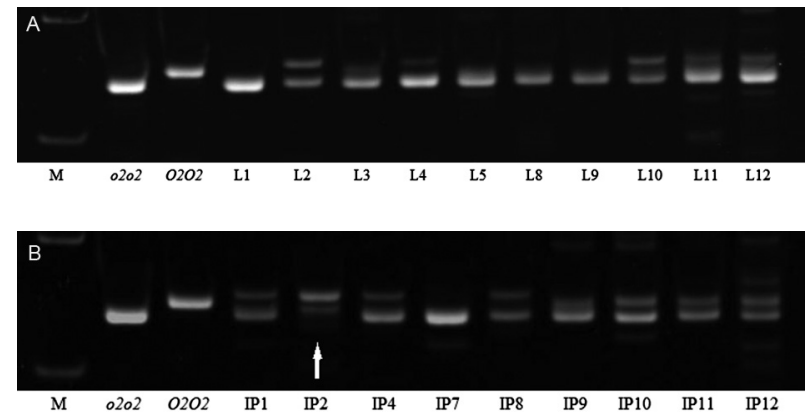

Figure 2 - Electrophoregrams of the opaque2 profiles obtained with umc1066 SSR marker for A) landraces and B) introduced populations. M - 100bp ladder DNA (lower band - 100bp, upper band - 200bp); 0202 - recessive allele control (opaque2 maize inbred line); 0202 - dominant allele control (standard maize inbred line). A - L1, L2, L3, L4, L5, L8, L9, L10, L11, L12 - landraces' bulked samples. B - IP1, IP2, IP4, IP7, IP8, IP9, IP10, IP11, IP12 - introduced populations' bulked samples. Arrow - the unknown (UA) allele.

Table 2 - Correlations between macronutrients (protein, starch and oil), tryptophan, quality index (QI) and kernel types determined by Pearson's correlation coefficient.

\begin{tabular}{llllll}
\hline & Starch & Oil & Tryptophan & Ql & Kernel type \\
\hline Protein NIR & $-0.525^{* *}$ & 0.147 & -0.188 & $-0.556^{* *}$ & -0.286 \\
Protein Kjeldahl & $-0.396^{*}$ & 0.077 & -0.224 & $-0.707^{* *}$ & -0.298 \\
Starch & & -0.286 & -0.191 & 0.033 & 0.130 \\
Oil & & 0.164 & 0.713 & -0.041 \\
Tryptophan & & & $0.845^{* *}$ & $0.389^{*}$ \\
Ql & & & & $0.447^{*}$ \\
\hline
\end{tabular}

NIR-Near Infrared Spectroscopy; ${ }^{*}-p<0.05 ;{ }^{* *}-p<0.01$. 
The two $\mathrm{O} 2 \mathrm{O} 2$ accessions had the lowest tryptophan content $(0.065 \%$ and $0.069 \%)$ (Figure 3). In all landrace 0202 accessions tryptophan content was in the range from $0.072 \%$ to $0.086 \%$ and in all 0202 accessions from $0.072 \%$ to $0.081 \%$. Tryptophan content in the 0202 introduced population (IP7) was $0.072 \%$ and in the 0202 populations in the range from $0.071 \%$ to 0.088 $\%$. In the IP2 accession in which an unknown allele was found, tryptophan content was $0.088 \%$.
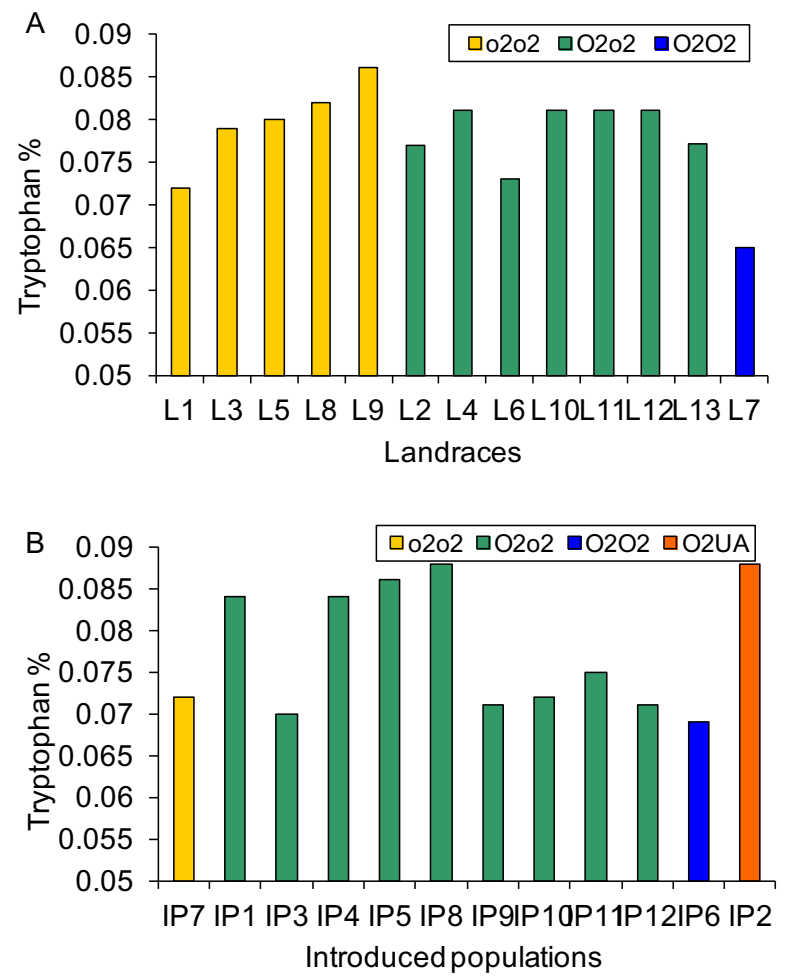

Figure 3 - Relation between the opaque2 locus profile (homozygous or heterozygous) obtained from bulked samples with umc1066 SSR marker and tryptophan content of the analyzed landraces (A) and introduced populations (B). Legend: 0202 - homozygous recessive; 0202 - heterozygous; 0202 - homozygous dominant; O2UA - heterozygous with 02 and an unknown allele.
Based on the allele profiles of the bulked samples and their tryptophan content, six accessions were chosen for the SSR analysis of individual kernels. Two homozygous recessive (o2o2) accessions L1 and IP7 had lower tryptophan content than L2, L10 and IP1 heterozygous $(\mathrm{O} 2 \mathrm{o} 2)$ accessions $(0.072 \%$ and $0.072 \%$ vs. 0.077 $\%, 0.081 \%$ and $0.084 \%$, respectively). On the other hand, IP2 accession had one of the highest tryptophan contents $(0.088 \%)$, despite having an allele that was unknown rather than the recessive 02 allele.

Dominant homozygous individuals were found in L1 and IP7 accessions (Table 3). All individuals of L1 and $96 \%$ individuals of IP7 accessions were homozygous recessive. In IP7 $4 \%$ were heterozygous for opaque2 locus, although the band characteristic for normal maize was not found in the bulked sample. One fifth to one quarter of the individuals were dominant homozygous for opaque2 in L2, L10 and IP1. Most of the samples were heterozygous, while recessive homozygous o2 allele was detected in $10 \%, 25 \%$ and $37 \%$ of individuals, respectively. In $10 \%$ of IP 1 accession an unknown allele (UA), absent in the bulk and positioned between the 02 and $\mathrm{O} 2$ bands, was detected.

Recessive homozygous 0202 individuals were not found in the IP2 accession. However, $8 \%$ of the individuals were 0202 heterozygous, although 02 allele was not detected in the bulked sample. An unknown band (also present in the bulk) was detected in $43.5 \%$ of individuals $140 \%$ in combination with $\mathrm{O} 2$ and $3.5 \%$ as homozygous UAUA). This band is located between the 02 and $\mathrm{O} 2$ bands (Figure 2), at the same position as the unknown band in IP1 accession (not presented).

\section{Discussion}

The values for typical kernel composition for the commodity yellow dent maize on a dry matter basis are $71.7 \%$ starch, $9.5 \%$ protein, $4.3 \%$ oil, $1.4 \%$ ash and $2.6 \%$ sugar (Watson, 2003). Compared with these data, all accessions analyzed by from MRI drought tolerant core collection had high protein contents (over $10.90 \%$ ), while high oil content (over $4.45 \%$ ) was found in four landraces and nine introduced populations. Analysis of

Table 3 - Opaque2 profiles (percentages of homozygous and heterozygous individuals) obtained with umc 1066 SSR marker on the individual kernels of the six accessions.

\begin{tabular}{|c|c|c|c|c|c|c|c|}
\hline \multirow{3}{*}{ Accession } & \multirow{3}{*}{ Tryptophan (\%) } & \multicolumn{6}{|c|}{ Opaque2 } \\
\hline & & \multirow{2}{*}{$\begin{array}{l}\text { Bulk } \\
\text { profile }\end{array}$} & \multicolumn{5}{|c|}{$\%$ of individuals } \\
\hline & & & 0202 & 0202 & 0202 & O2UA* & $U_{A U A}$ * \\
\hline$\overline{\mathrm{L} 1}$ & 0.072 & 0202 & 100 & - & - & - & - \\
\hline IP7 & 0.072 & 0202 & 96 & 4 & - & - & - \\
\hline L2 & 0.077 & 0202 & 10 & 68 & 22 & - & - \\
\hline L10 & 0.081 & 0202 & 25 & 50 & 25 & - & - \\
\hline IP1 & 0.084 & 0202 & 37 & 42 & 10.5 & 10.5 & - \\
\hline IP2 & 0.088 & 02UA & 0 & 8 & 44.5 & 40 & 3.5 \\
\hline
\end{tabular}

L - landraces; IP- Introduced populations; *UA - unknown allele; 0202 - homozygous recessive; 0202 - heterozygous; 0202 - homozygous dominant; 02UA heterozygous with 02 and an unknown allele; UAUA - homozygous for the unknown allele. 
11 Mexican landraces, 32 white and six yellow hybrids revealed that landraces had higher average protein and oil contents as compared to hybrids - average protein and oil contents were $11.1 \%$ and $4.9 \%$ for the landraces, $9.7 \%$ and $3.7 \%$ for white hybrids and $9.8 \%$ and $3.2 \%$ for yellow hybrids (Vásquez-Carrillo et al., 2011). Similar values for these macronutrients were also found among 1245 accessions from different parts of the world (Berardo et al., 2009). Starch content among MRI accessions was low, except in the five introduced populations in which it was at the hybrid level (over $70 \%$ ). Lower starch content compared to hybrids was also found in accessions from the Gemplasm Enhancement of Maize (GEM) project (Singh et al., 2001).

Protein content was also determined by the Kjeldahl method, assuming that this method would be more sensitive than NIR analysis. Pearson's correlation coefficient for these two methods was positive at $p<0.01$. Higher correlation for protein content (as well as for tryptophan and lysine contents) calculated by NIR and the colorimetric method was obtained in another experiment (Rosales et al., 2011), in which it was concluded that NIRS models can be used to support QPM breeding where a very high number of of samples have to be analyzed in a short time. However, for small scale analysis as the one performed in our work, the colorimetric method is more appropriate, since, in order to achieve a high level of confidence, NIR requires a development of the calibration curve that is based on a large and diverse set of samples and validation chemical analysis methods.

For many purposes not only the concentration but also the structure of macronutrients is important (Pollak and Scott, 2005). In this study, analysis of tryptophan content, one of the essential amino acids, was carried out. The limit values recommended for QPM selection are $0.075 \%$ for tryptophan and $0.8 \%$ for QI (Vivek et al., 2008). High tryptophan content was detected in the majority of the accessions. Fifteen accessions had a tryptophan content over the limit, eight in the range from $0.070 \%$ to $0.074 \%$ and two slightly below $0.070 \%$.

Tryptophan content in normal maize is usually under $0.060 \%$. In Ignjatovic-Micic et al. (2009) the tryptophan content in B73 and Oh43 inbred lines was 0.059 $\%$ and $0.054 \%$, respectively. Similar values of $0.059 \%$ for white hybrid ZP74b and $0.052 \%$ for yellow hybrid ZP636, as well as a somewhat higher content of $0.065 \%$ in yellow hybrid ZP434 were obtained in a biochemical analysis of maize hybrids (Zilic et al., 2011). Across different genetic backgrounds lower limits of tryptophan in 0202 maize overlap with its upper limits in normal maize. To confirm if the accessions with ambiguous tryptophan content were opaque2 genotypes SSR analysis with specific marker umc1066 was carried out. Two accessions with tryptophan content below 0.070 were found to lack o2 allele. Moreover, they had QI typical for normal maize. Presence of recessive 02 allele was detected in the five accessions with tryptophan content in the range from $0.070 \%$ to $0.074 \%$, confirming that they were opaque 2 genotypes. On the other hand, IP2 was one of the two accessions with the highest tryptophan content and highest QI, but within this population 02 was detected only in $8 \%$ of the heterozygous samples. As tryptophan content is not elevated when 02 is not homozygous recessive, these results point to the presence of some other high lysine/tryptophan mutation (e.g. floury2 or opaque7), which, however, with different modes of action result in high tryptophan/lysine genotypes (Schmidt et al., 1987; Coleman et al., 1997; Miclaus et al., 2011).

Analysis of individuals within opaque2 heterozygous accessions (determined by bulk sample analysis) revealed different percentages of the presence of 0202 , from approximately one tenth to one third. High tryptophan content within these accessions, despite low presence of recessive homozygous opaque2 individuals, indicates that these individual plants had much higher tryptophan content than that measured for the whole population. It could also indicate the possible presence of amino-acid modifier/enhancer genes, considering that some landraces/introduced populations that were completely homozygous recessive for opaque2 had lower values of tryptophan content. Several enhancer genes have been identified (Wang et al., 2001; Wu et al., 2002) that affect the relative levels of lysine and tryptophan content in the grain endosperm (Moro et al., 1996).

In some cases bulk analysis did not detect $\mathrm{O} 2$ (IP7) or o2 (IP2) alleles, although they were detected in a small percent as 0202 heterozygous loci in the analysis of individual kernels. This could be explained by the fact that alleles present in small percent can be missed in bulk analysis (Reif et al., 2005). In IP1 and IP2 accessions an unknown band (allele) was detected, positioned between the 02 and $\mathrm{O} 2$ bands. Both populations originate from Iran indicating that this band could be connected with their geographic origin. Most probably this allele is of dominant action, as it was present only as the heterozygous O2UA locus in IP1 and also the homozygous UAUA individuals were detected in a small percentage $(3.5 \%)$ of the IP2 accession. Since those two accessions had the highest tryptophan levels, there could be two possible explanations. The first one is that it was the consequence of some other gene(s) beside o2 (flowery2 or opaque7). The second one is that $U A$ allele increases the tryptophan level, and if such is the case, this allele should be over-dominant to $\mathrm{O} 2$ allele. It would be worthwhile testing if $U A$ has any influence on an increase in tryptophan content and its sequence should be identified.

High kernel type scores, absence of completely opaque kernels and presence of over $80 \%$ of hard endosperm kernels were found in 0202 accessions. The soft, opaque endosperm in 0202 genotypes is the consequence of an 02 allele pleiotropic effect which has an influence on zein synthesis. However, a distinct genetic system comprising minor modifying genes (endosperm hardness modifier genes) influence gamma zein production and convert soft (opaque) into hard (vitreous) endosperm - such 0202 grains with hard endosperm having 
approximately double the amount of gamma zein in the endosperm as compared to the o2-only mutants (Danson et al., 2006, Wallace et al., 1990). The presence of a high percentage of hard endosperm kernels in the 0202 accessions from the drought tolerant core clearly implies a presence of the endosperm hardness modifier genes.

Kernel type 3 was found in a small percentage (app. $5 \%$ ) of both $\mathrm{O} 2 \mathrm{O} 2$ genotypes. Some other opaque or floury gene could be present in these accessions, considering that according to the LSD test their tryptophan content was no different $(p>0.01)$ from some high tryptophan accessions. Also, the possibility of some other opaque or floury gene(s) action in the IP2 accession that has already been described is further enhanced by the presence of opaque kernels. Kernel types 3 and 4 were found in 0202 accessions, as could have been expected, as bulk samples encompassed homozygous recessive individuals.

\section{Conclusion}

The accessions can be used as sources of new desirable alleles for food and feed improvement. Moreover, several accessions (e.g. L3, IP2 and IP8) have been identified that have high contents of protein, oil and tryptophan concurrently. Some of the high tryptophan accessions did not have the recessive opaque2 mutation, thus indicating the presence of some other mutation, such as fluory2 or opaque7. The drought tolerant core collection was selected in field trials performed in both sub-tropical and temperate zones. Hence, these genotypes could be used for breeding maize adapted to both environments.

\section{Acknowledgement}

This research was supported by the Ministry of Education, Science and Technological Development of Republic of Serbia through the project TR31028 Exploitation of maize diversity to improve grain quality and drought tolerance.

\section{References}

Babic, M.; Andjelkovic, V.; Mladenovic Drinic, S.; Konstantinov, K. 2011. The conventional and contemporary technologies in maize (Zea mays L.) breeding at Maize Research Institute, Zemun Polje. Maydica 56: 155-164.

Baye, T.M.; Pearson, T.C.; Settles, A.M. 2006. Development of a calibration to predict maize seed composition using single kernel near infrared spectroscopy. Journal of Cereal Science 43: 236-243.

Berardo, N.; Mazzinelli, G.; Valoti, P.; Lagana, P.; Redaelli, R. 2009. Characterization of maize germplasm for the chemical composition of the grain. Journal of Agricultural and Food Chemistry 57: 2378-2384.

Coleman, C.E.; Clore, A.M.; Ranch, J.P.; Higgins, R.; Lopes, M.A.; Larkins, B.A. 1997. Expression of a mutant alpha-zein creates the floury2 phenotype in transgenic maize. Proceedings of the National Academy of Sciences of the United States of America 94: 7094-7097.
Danson, J.W.; Mbogari, M.; Kimani, M.; Lagat, M.; Kuria, A.; Diallo, A. 2006. Marker assisted introgression of opaque-2 gene into herbicide resistant elite maize inbred lines. African Journal of Biotechnology 5: 2417-2422.

Flint-Garcia, S.A.; Bodnar, A.L.; Scott, M.P. 2009. Wide variability in kernel composition, seed characteristics, and zein profiles among diverse maize inbreds, landraces, and teosinte. Theoretical and Applied Genetics 119: 1129-1142.

Ignjatovic-Micic, D.; Markovic, K.; Ristic, D.; Mladenovic-Drinic, S.; Stankovic, S.; Lazic-Jancic, V.; Denic, M. 2009. Variability analysis of normal and opaque2 maize inbred lines. Genetika 41: 81-93.

Krivanek, A.F.; De Groote, H.; Gunaratna, N.; Diallo, A.; Friesen, D. 2007. Breeding and disseminating quality protein maize (QPM) for Africa. African Journal of Biotechnology 6: 312-324.

Miclaus, M.; Wu, Y.; Xu, J.H.; Dooner, H.K.; Messing, J. 2011. The maize high-lysine mutant opaque7 is defective in an acylCoA synthetase-like protein. Genetics 189: 1271-1280.

Moro, G.L.; Habben, J.E.; Hamaker, B.R.; Larkins, B.A. 1996. Characterization of the variability for lysine content in normal and opaque-2 maize endosperm. Crop Science 36: 1651-1659.

Nurit, E.; Tiessen, A.; Pixley, K.; Palacios-Rojas, N. 2009. A reliable and inexpensive colorimetric method for determining proteinbound tryptophan in maize kernels. Journal of Agricultural and Food Chemistry 57: 7233-7238.

Pollak, L.M.; Scott, M.P. 2005. Breeding for grain quality traits. Maydica 50: 247-257.

Reif, J.C.; Hamrit, S.; Heckenberger, M.; Schipprack, W.; Maurer, H.P.; Bohn, M.; Melchinger, A.E. 2005. Genetic structure and diversity of European flint maize populations determined with SSR analysis of individuals and bulks. Theoretical and Applied Genetics 111: 906-913.

Rogers, S.O.; Bendich, A.J. 1988. Extraction of DNA from plant tissues. Plant Molecular Biology Manual A6, 1-10.

Rosales, A.; Galicia, L.; Oviedo, E.; Islas, C.; Palacios-Rojas, N. 2011. Near-Infrared Reflectance Spectroscopy (NIRS) for protein, tryptophan, and lysine evaluation in Quality Protein Maize (QPM) breeding programs. Journal of Agricultural and Food Chemistry 59: 10781-10786.

Rosegrant, M.W.; Msangi, S.; Ringler, C.; Sulser, T.B.; Zhu, T.; Cline, S.A. 2008. International model for policy analysis of agricultural commodities and trade (IMPACT): model description. International Food Policy Research Institute, Washington, DC, USA. Available at: http//:www.ifpri.org [Accessed May 1, 2011]

Schmidt, R.J.; Burr, F.A.; Burr, B. 1987. Transposon tagging and molecular analysis of the maize regulatory locus opaque-2. Science 238: 960-963.

Singh, S.K.; Johnson, L.A.; Pollak, L.M.; Hurburgh, C.R. 2001. Compositional, physical, and wet-milling properties of accessions used in Germplasm Enhancement of Maize Project. Cereal Chemistry 78: 330-335.

Sofi, P.; Wani, S.A.; Rather, A.G.; Wani, S.H. 2009. Quality Protein Maize (QPM): genetic manipulation for the nutritional fortification of maize. Journal of Plant Breeding and Crop Science 1: 244-253.

Uarrota, V.G.; Schmidt, E.C.; Bouzan, Z.L.; Maraschin, M. 2011. Histochemical analysis and protein content of maize landraces (Zea mays L.). Journal of Agronomy 10: 92-98. 
Vázquez-Carrillo, G.; García-Lara, S.; Salinas-Moreno, Y.; Bergvinson, D.J.; Palacios-Rojas, N. 2011. Grain and tortilla quality in landraces and improved maize grown in the highlands of Mexico. Plant Foods for Human Nutrition 66: 203-208.

Vivek, B.S.; Krivanek, A.F.; Palacios-Rojas, N.; Twumasi-Afriyie, S.; Diallo, A.O. 2008. Breeding Quality Protein Maize (QPM): protocols for developing QPM cultivars. CIMMYT, Mexico, DF, Mexico.

Wallace, J.C.; Lopes, M.A.; Paiva, E.; Larkins, B.A. 1990. New methods for extraction and quantification of zeins reveal a high content of gamma-zeins in modified opaque-2 maize. Plant Physiology 92: 191-196.

Wang, X.; Woo, Y.; Kim, C.S.; Larkins, B.A. 2001. Quantitaive trait locus mapping of loci influencing elongation factor 1 content in maize endosperm. Plant Physiology 125: 1271-1282.

Watson, S.A. 2003. Description, development, structure and composition of the corn kernel. p. 69-106. In: White, P.J.; Johnson, L.A., eds. Corn: chemistry and technology. 2ed. American Association of Cereal Chemists, St. Paul, MN, USA.
White, P.J. 2001. Properties of corn starch. p. 29-54. In: Hallauer, A.R., ed. Specialty corns. CRC Press, Boca Raton, FL, USA.

Wright, S.I.; Bi, I.V.; Schroeder, S.G.; Yamasaki, M.; Doebley, J.F.; McMullen, M.D.; Gaut, B.S. 2005. The effects of artificial selection on the maize genome. Science 308: 1310-1314.

Wu, R.L.; Lou, X.Y.; Ma, C.X.; Wang, X.L.; Larkins, B.; Casella, A.G. 2002. An improved genetic model generates highresolution mapping of QTL for protein quality in maize endosperm. Proceedings of the National Academy of Sciences of the United States of America 99: 11281-11286.

Yamasaki, M.; Tenaillon, M.I.; Bi, I.V.; Schroeder, S.G.; SanchezVilleda, H.; Doebley, J.F.; Gaut, B.S.; McMullen, M.D. 2005. A large-scale screen for artificial selection in maize identifies candidate agronomic loci for domestication and crop improvement. Plant Cell 17: 2859-2872.

Zilic, S.; Milasinovic, M.; Terzic, D.; Barac, M.; Ignjatovic-Micic, D. 2011. Grain characteristicsand composition of maize specialty hybrids. Spanish Journal of Agricultural Research 9: 230-241. 